\section{Rich in Tradition, Progressive in Practice, Building Our Future Together}

\author{
Barry Finlay, Gail Phillips, Alison Cail \\ and Lindsay Clarke
}

"Teaching is a passionate vocation... Passionate teachers need interaction with, and support from others to avoid becoming exhausted. All teachers need to inspire each other through collaborative work, to take advantage of the power of emotional resources, and to provide the interpersonal safety nets when the going gets rough."

Michael Fullen

I n the Halton District School Board we appreciate the power of relationships, not only at an interpersonal level, but also among all aspects of the teacher/learner dynamic. Our Partners in the Classroom program is designed to optimize the use of these relationships to ease the transition to the teaching profession for our newest members of the Halton family while at the same time modelling the behaviours that we want to see across our system.

"Pervasive caring is a criterion for school effectiveness"

Much is written these days about the importance of alignment for effectiveness in all organizations. Schools that have "turned around" and have witnessed significant gains in the achievement levels of all of their kids, have done so through aligning all school behaviours to this goal; however, there remains no more important relationship than the teacher to the child.

In Halton, we believe that just as every student is important, so is every teacher - thus our Partners Program. This year long orientation to the teaching profession and to the Halton District School Board sets the stage for a career of professional growth and development through a combination of professional learning activities and a one-one mentorship relationship. The value of mentorship is grounded in research but further evidence of its impact on our new teachers to Halton will be presented first hand later in this article.

We are committed to...

promoting and providing ongoing professional growth for all staff

During the past couple of years, the Halton District School Board has gone through a process of creating a Strategic Plan including a new Mission Statement and Guiding Principles. As evidence of our commitment to our teachers, every teacher in the Board had the opportunity to provide input to this plan. Although this may not be unique you may be thinking, the fact that over 4,000 Halton staff in groups of approximately 25 , were in the same room at the same time giving their input to 144 trained facilitators is a testament to how they are valued. We live our Mission and Guiding Principles.

\section{MISSION}

The Halton District School Board is committed to providing the highest quality education which prepares our students for success as responsible, participating citizens of the global community.

As you are about to read, the Partners Program is simply an introduction for new teachers to Halton to a life of professional learning. Its effectiveness will become clear as you read the comments of its creator and two of its recent participants.

"It is a fact that in the right formation, the lifting power of many wings can achieve twice the distance of any bird flying alone."

(Anonymous)

In every profession, the novice must learn to apply their learnings for the first time. Each must transfer what they were taught as students to what they must do as practitioners in their chosen profession. The teaching profession is, however, unique. The design of school buildings and the organization of the day can physically isolate its newest members from contact with their colleagues for much of the time. Too often, during the first years of "on the job training", teachers have to master their craft through trial and error and in an isolated environment.

The Halton District School Board hired approximately 150 elementary and 75 secondary teachers this year. In the next few years, many other new teachers will join Halton's staff. This significant rate of change challenges us to integrate new staff and to provide a supportive teaching and learning environment.

We believe that this first year of a teacher's career is crucial and that our experienced staff can provide invaluable guidance and support for the newest members of the profession. For this reason, Partners in the Classroom combines 
a solid professional development plan with mentor support. Partner pairs are formed to combine a Faculty graduate with an experienced mentor partner in the school. Since the focus for growth and change is the school, the concept of a school based mentor partner ensures ongoing, practical support.

The Partners in the Classroom program is designed to engage new staff in a process of interactive professionalism. Specific expectations of the program are to:

- provide orientation for new teachers and assist their integration into the professional and social life of their school communities;

- provide support to promote teachers' professional and personal self esteem;

- enhance the acquisition and refinement of knowledge, skills and attitudes related to effective classroom instruction;

- encourage habits of reflection and self evaluation of teaching practices; and

- foster a commitment to ongoing professional growth.

The content of the program balances large group input sessions and smaller divisional (e.g., Primary, Junior, Intermediate) and specialist (e.g., Core French, Secondary Math \& Science) sessions with school based coaching.

The large group and smaller divisional and specialist sessions that are offered between August and May focus on five key aspects of the teaching role:

- Setting the Climate for Learning: Strategies (e.g., Tribes) which create a positive learning environment in the classroom;

- Instruction for Success: A series of workshops which focus on the components of effective classroom management as well as teaching and learning strategies;
- Assessing the Learning: Sessions which highlight the components of effective assessment and evaluation;

- Communicating the Learning: Sessions which deal with the development of positive relationships and the skills of effective communication with parents, administrators, colleagues and students;

- Reflection and Renewal: Feedback which includes evaluation of the program and future needs.

\section{"Two Day August Program \\ Helps Teachers Cope with First Day Stress"}

At the end of August this year, new teachers and their mentors spent two days together preparing for the upcoming school year. The energy in the room was incredible! The first day focused on setting the climate for learning and planning for the first day and weeks of school as well as learning about the "Nitty Gritty" information which is specific to each school (e.g., photocopying procedures, the names of key people in the school such as secretarial and care-taking staff, the teacher-librarian and the Special Education Resource Teacher). Teachers worked in their family of school groupings and also in smaller divisional and specialist groups. These smaller groups are lead by "Super Mentors" who are part of the Partners in the Classroom planning team. These mentors are Consultants and Coordinators in the curriculum department or master classroom teachers. They provide support and leadership as well as practical ideas to a specific group (e.g., JK/SK, Core French, Music). Store fronts were also set up on this first day so that new staff had an opportunity to meet and make connections with the Curriculum Department Consultants and Coordinators.
The second day in August focussed on Classroom Management. Barrie Bennett spent the day with the new teachers looking at the complex art of teaching and classroom management. Teachers left the session with very concrete and practical suggestions and ideas. A follow-up after-school session was held at the beginning of October. At this time, teachers had an opportunity to continue their learning with Barrie and each other and to talk about specific classroom management issues that had arisen during the first month of school.

Recognizing that everyone is tired at the end of a teaching day, the Partners in the Classroom program combines after-school with half-day sessions for which supply coverage is provided by the Board. In September and October, half-day inservice sessions with a focus on Assessment and Evaluation were held for division and subject speciality groups. Follow-up half-day sessions for these groups will also be held in January.

\section{"Between the large and smaller group sessions, the new teachers interact for- mally and informally with their mentors."}

Between the large and smaller group sessions, the new teachers interact formally and informally with their mentors. Discussion may focus on teaching and learning strategies, resources, school routines, record keeping, classroom management and planning. It takes a special kind of person to be a good mentor. The key characteristic is a sincere desire to be involved with and support the new teacher. A good mentor is one who is a skillful teacher, able to share effective teaching and learning strategies, knowledgeable 
about the curriculum, a good listener, an open communicator and sensitive to the needs of the new teacher. We are fortunate to have so many experienced teachers in Halton who are willing to provide support and leadership for new staff.

A strong mentor-partner relationship significantly benefits the beginning teacher, not only during the first year but also in years to come. Mentor partners experience a significant leadership opportunity as they contribute to the development of new professionals. Mentors also benefit from their interaction with the new teachers. The first year teacher often brings an enthusiasm that is infectious, as well as a different way of approaching teaching. The partnerships are two-way learning situations. The students in Halton benefit from a learning environment in which colleagues support each other and grow together professionally. The Halton District School Board retains and nurtures promising new staff while enhancing the professional growth of experienced teachers. Over the years, the feedback from all who are involved with the program has been extremely positive.

When the teacher recruitment process begins each year, the Partners in the Classroom program is one of the reasons why new teachers look to Halton as the place where they would like to begin their career. Next August a new group of teachers will be welcomed into the Board and will come together once again with their mentors and Halton staff to begin the process of teaching and learning together.

\section{On a personal note...}

What the Partnership

Program has meant to us
We are now second-year teachers, proud to have successfully completed our first year of teaching, and equally proud to be in the midst of our second. We continue to inspire and to be inspired by those around us. As second-year teachers we can now reflect how the Halton District School Board's Partners Program fostered our professional growth. In fact, we continue to reap its benefits.

\section{"They believed in our ideas and abilities, thus giving us the added confidence to suc- ceed in our first year of teaching."}

Similar to beginning any new career we were elated, full of promise and ideas. We were passionate about our new paths, and looked forward to growing with our profession. Just the same, we couldn't help but feel some apprehension: we were to be moulding the future. Luckily, we were not alone. Rather, we were matched with mentors through Halton's Partners Program. They provided curriculum and programming advice, and acted as great emotional resources when times seemed tough. They believed in our ideas and abilities, thus giving us the added confidence to succeed in our first year of teaching.

This idea of partnership, however, extends well beyond our immediate mentors. We have found that in both of our schools, the idea of partnership filters through many levels. Our fellow colleagues, administrators, secretarial and custodial staff all demonstrate a willingness to be actively involved in our careers. They can be counted on for most anything. Their commitment to the teaching profession and to each other is evident.

Along with support and guidance, the Partnership Program offers various leadership opportu- nities. Our mentors, who gladly offered feedback and advice, are prime examples of this. Perhaps with any other partnership program, the role of leader would begin and end with the role of mentor. We quickly discovered, however, that this was not the case with Halton District's Partners Program. We served as both providers and recipients. For example, just this past year we were invited to represent the School Board in recruiting new teacher candidates. This allowed us the opportunity to speak of our own personal experiences, and to share with up-coming teachers the premise of this particular program. We were able to reciprocate the guidance and leadership received only earlier that year.

The Halton District School Board's Partners Program has been a welcoming introduction to our teaching careers. It has fostered professional growth, has provided support and guidance, and has enhanced the skills needed to be a successful educator. Undoubtedly, it is a program with benefits for all: students, new teacher partners and mentor partners alike.

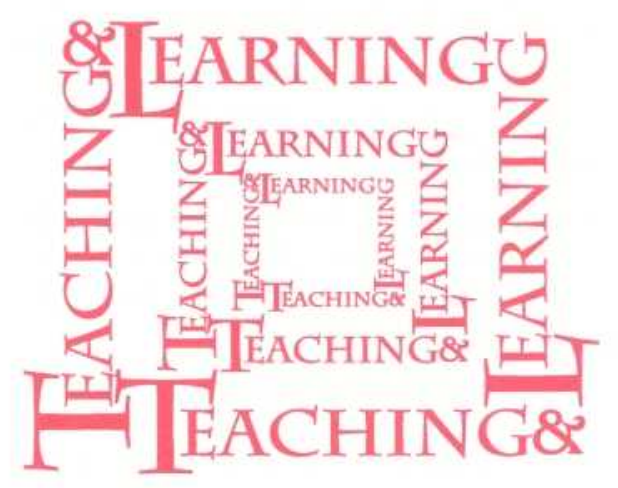

